\title{
Representaciones mentales y prototipos: el proceso de comunicación desde el punto de vista cognitivo ${ }^{145}$
}

"Maga, tú y todavia tú.

Marelle, 62, note cognitive"
Miguel Ángel Mahecha B. ${ }^{140}$

Profesor área de Lingüistica

Facultad de Educación

miguelangel.mahecha@usco.edu.co
En este trabajo nos ocuparemos de un referente denominado 'representaciones mentales' y sus respectivos 'prototipos' presentes en el proceso de la comunicación. Este tema puede ser considerado desde diversos marcos teóricos pero nuestro aporte se fundamenta en el marco teórico global de la lingüística cognitiva. Es por eso que la presentación estará dividida en (\$1) una ambientación general sobre lo que se entiende por lingüística cognitiva y los enfoques de Cambridge y California, (\$2) las particularidades de la comunicación desde la 'emotividad' y jerarquización de prototipos y sus representaciones a través de los mapas cognitivos.

\section{La lingüística cognitiva}

\subsection{Lineamientos generales}

Tal como se mencionó en Mahecha (2011, 245268) se podría afirmar que la 'lingüística cognitiva' forma parte del complejo teórico denominado ciencia cognitiva en razón, entre otros muchos casos, a la consideración de una perspectiva interna sobre el lenguaje, tal como lo sugieren Rouveret $(2004,27-71)$ y Rastier (2011,101-128). Dicho complejo teórico puede ser considerado, ya lo dijimos, como un paradigma reciente de la ciencia actual y que busca develar el proceso de cognición de la mente humana, a través de los diversos métodos de las disciplinas involucradas tales como la inteligencia artificial, la psicología cognitiva, la antropologia, la filosofía de la mente, la neurociencia y la propia lingüistica (i.e. la lingüística de cuño chomskyano). Es conveniente recordar además que la ciencia cognitiva no se interesa sólo en el proceso de cognición de la mente humana sino también en el de los mecanismos abstractos de las máquinas; de ahí que exista la variante computacionalista.

\footnotetext{
${ }^{145}$ Artículo de reflexión no derivado de investigación. Fue redactado durante el periodo 2011-2 como actividad complementaria de los cursos de lingüística y de Lenguaje y Evolución Humana y hace parte de la redacción de un libro sobre la enseñanza de la lingüística. Fue programado en la respectiva agenda académica del docente. Lo explicitado en el presente texto es una invitación a la lectura del libro Antología de Lingüistica Cognitiva, preparado por el autor del artículo. El título original de este artículo era "Representaciones mentales y prototipos: la constitución del plano cognitivo", pero se ha modificado en aras de una aplicación y contextualización adecuadas a la dinámica mental de los estudiantes y colegas cuyos conocimientos de teoria lingúistica están aún en proceso de consolidación.

${ }^{146}$ Orienta los cursos de Introducción a la Lingüistica, Lingüistica y el curso electivo de Lenguaje y Evolución Humana. Es editor de la revista institucional Entomos y Asistente editorial de la revista Paideia Surcolombiana.
} 
El adjetivo 'cognitivo(a)' implicaria que cada una de las disciplinas se ocuparia de explicar un aspecto específico de la cognición a partir de la formulación de su objeto de estudio que deberá coincidir por supuesto con el enfoque 'cognitivo', pues éste trata de explicar cuestiones tradicionales (p.ej. el conocimiento humano) a la luz de los estudios sobre la granularidad cerebral, es decir, el funcionamiento neuronal y el procesamiento de la información. Para el caso de la lingüística es el 'lenguaje', la facultad ingénita que permite conceptualizar, representar, significar. La significación debe ser considerada pues como algo relativo a la cognición en general, es decir, al poseer un sentido, se posee un concepto que es capaz de activar representaciones internas que pueden ser de diferente naturaleza (lingüística y no lingüística). En los acápites 2 y 3 se ilustrarán estos casos.

Si revisamos el texto de Cuenca y Hilferty ${ }^{147}$, uno de los primeros textos introductorios escritos en español sobre lingüística cognitiva, encontramos datos ambiguos sobre las primeras posturas cognitivas -evidentes claro está en la lingüística, pues éstas habían sido ya sistematizadas con antelación en los modelos teóricos de la gramática generativa chomskyana y de la psicolingüística. Dice pues el texto: "[...] Podemos decir que la lingüistica cognitiva nace en California, que sus padres son George Lakoff (Berkeley), uno de los primeros representantes de la extinguida semántica generativa y Ronald Langacker (San Diego), también vinculado al generativismo en el pasado, y que el año de tan feliz acontecimiento es 1987. Si bien mucho antes ya se puede hablar de trabajos cognitivos, y se podria decir que la gestación comenzó entre finales de los 70 y principios de los 80,1987 es el año de publicación de dos libros fundamentales en este paradigma [...] Women, Fire and Dangerous Things (Lakoff) [...] Foundations of Cognitive Grammar: Theoretical Prerequisites (Langacker)." 148

No obstante, en los diversos escritos de Chomsky así como en sus declaraciones personales, se pueden apreciar comentarios pioneros sobre la revolución cognitiva y sus implicaciones para (y desde) la lingüística. ${ }^{149}$

En la presentación que hace Gardner de la ciencia lingüistica ${ }^{150}$ como una de las ciencias cognitivas, el modelo teórico lingüístico que se relaciona si y sólo si con la revolución cognitiva es el modelo mentalista chomskyano. En ese orden de ideas podemos afirmar que la lingüística cognitiva es el modelo mentalista chomskyano. En ese orden de ideas podemos afirmar que la lingüistica cognitiva, sus principios y modelos tienen su asiento en los planteamientos chomskyanos. Gardner asi lo corrobora: "Pero debe añadirse que en ninguna otra ciencia cognitiva contemporánea ha sido tan decisiva e irreemplazable la obra de un único individuo. No es exagerado afirmar que la historia de la lingüística moderna es la

\footnotetext{
47 Maria Joseph Cuenca y Joseph Hilferty. 1999. Introduccion a la linguistica cognitiva. (Barcelona, Ariel: 1999)

${ }_{148}$ Resultaria interesante confrontar -para sacar inicialmente algunas conclusiones- 10 afirmado por estos autores y lo registrado por Langacker, 1991: "A symposium organized by René Dirven and Held in Duisburg in the spring of 1989 marked the bird of cognitive linguistics as a broadly grounded, self conscious intellectual movement. At the conference, initiation of the journal Cognitive Linguistics was announced and plans were made to form the International Cognitive Linguistics Association. Additionally, agreement was reached to launch the monograph series Cognitive Linguistics Research, and I was prevailed upon to prepare the first volume in that series. The result is before you. My own self-conscious efforts at formulating a cognitively realistic linguistic theory began precisely thirteen years prior to the Duisburg symposium. Within a few years these efforts gave rise to a coherent conceptual framework, originally called 'space grammar' and later rechristened as 'cognitive grammar', that I have continued to refine, develop, and articulate ever since."

${ }^{140}$ Chomsky, 1977, 1985, 1989, 1992, 2002, 2005.

${ }^{150}$ Gardner, $1988,204-46$.
} 
historia de las ideas de Chomsky y de las variadas reacciones que la comunidad científica mostró frente a ella." ${ }^{151}$

Chomsky ha desarrollado a lo largo de sus diferentes propuestas ${ }^{152}$ un programa biolingüistico en donde defiende la tesis de que comprender el lenguaje humano es comprender la naturaleza humana. Precisamente la revolución cognitiva ve en el comportamiento la actuación- y sus efectos, no un objeto de estudio sino una fuente de información que arroja datos sobre los mecanismos subyacentes internos de la mente humana. La biolingüística se constituye pues en un dominio hibrido (biología, lingüística, psicologia) de selección epistemológica y que contiene el programa de la lingüística cognitiva o si se quiere, del lenguaje. Esta última insiste en la 'naturaleza cognitiva del lenguaje' $y$, siguiendo a Cuenca y Hilferty, puede ser experiencial u objetiva ${ }^{153}$. Como el interés es la facultad del lenguaje, hay una pregunta clave: " $¿$ Es el lenguaje una capacidad diferenciada y autónoma con respecto a la cognición humana 0 , por el contrario, interactúa con los demás sistemas cognitivos y no se puede entender ni se debe estudiar aislado de ellos?" 154

En el libro que hemos venido citando, encontramos que uno de los retos que debe enfrentar la lingüistica cognitiva es precisar su propio objeto de estudio y para esto se requiere unificar los diferentes enfoques cognitivos como por ejemplo los de la mente seca y la mente húmeda ${ }^{155}$. Esto quiere decir que su base epistemológica está aún en constitución. Además, se le ha criticado el utilizar conceptos clásicos dentro de esquemas nuevos (non nova, sed nove). Si bien las críticas no están lejos de la realidad, los presentadores de la lingüística cognitiva defienden su escogencia argumentando que es una suerte de propuesta 'recicladora', en sus términos, "toma el material de varias fuentes, pero ofrece un producto diferente dándole una nueva forma, dotándolo de una definición renovada, incardinándolo en otro sistema de presupuestos y llevándolo hacia terrenos inexplorados." 156

Así las cosas, podemos afirmar que la lingüistica (cognitiva) es la lingüística del siglo XXI. Al haber hecho la lingüística un acopio de reflexiones y de métodos a lo largo de su historia, ya puede asumir y enfrentar los retos que plantea el trabajo con la facultad del lenguaje. Hasta donde sabemos, fue en los siglos XVI y XVII que se intentó abordar la 'gramática universal' cuyo método deductivo buscaba ocuparse de los 'principios inmutables del lenguaje' que formaban parte de la naturaleza humana. Es más, la intuición de Humboldt de que "una lengua se basa en un sistema de reglas que determinan la interpretación de sus infinitas oraciones" quedaba apenas esbozada porque no existian los recursos técnicos para

${ }^{151} \mathrm{Op}$. Cit. Las negrillas son nuestras. Pero no solo Gardner. Pierre Jacob, filósofo cognitivo considera que la lingüistica, desde la perspectiva chomskyana es la que abre el camino al enfoque cognitivo: "Il y plusieurs manières de définir la linguistique. J'admets pour ma part la définition qu'en donne Chomsky selon laquelle la linguistique est l'étude de la faculté humaine de langage. Comprise en ce sens, la linguistique est l'étude d'une capacité cognitive humaine : la capacité grâce à laquelle tout être humain est capable d'énoncer et de comprendre (Comunicación personal 2006).

${ }^{152}$ Para conocer la evolución de los modelos chomskyanos, aparte de los textos del propio Chomsky, véase Rouveret, 1987, Pollock, 1997,

Boeckx y Hornstein, 2007, Tania Reinhart, 2007 y P. Jacob, 1984 y 2007.

${ }^{153}$ Para lo experiencial el pensamiento responde a una estructura ecológica; tiene carácter corpóreo, es decir se basa en la experiencia corporal humana; es imaginativo y sólo puede describirse por modelos cognitivos. Para lo objetivista, pensar es manipular simbolos abstractos que se relacionan directamente con el mundo. El pensamiento es atomistico e independiente del cuerpo humano. Es igualmente lógico y puede ser formalizado y descrito a partir de valores de verdad.

${ }^{154}$ Cuenca y Hilferty, 1999, 17.

${ }^{155}$ Sobre estos enfoques véase Kosslyn y Koenig, 1992 asi como Juan José Botero et al., 2000.

${ }^{156}$ Página 207 
desarrollarla ${ }^{157}$. Es pues en el espacio de la ciencia cognitiva en donde las diferentes aproximaciones sobre el lenguaje pueden unificarse para determinar cómo se relaciona con otras capacidades cognitivas, es decir, identificar los correlatos físicos de la cognición. En resumen, la lingüistica cognitiva requiere de un método científico (teórico-experimentalaplicado) interdisciplinar que articule por un lado, teorías lingüísticas y epistemológicas con el fin de comprender y de fundamentar al mismo tiempo la génesis de los significados, de los conocimientos, sin hacer abstracción de las condiciones y los medios de su emergencia y difusión en la diversidad de las lenguas y las culturas. Es más, la lingüística cognitiva podría considerarse una ciencia de la cultura cuyos objetos son las obras humanas ${ }^{158}$. El sentido es algo importante y los métodos que se proponen para analizarlo buscan establecer tanto su legitimidad así como su relación con lo formalizable. Podríamos aventurar entonces, siguiendo a Rastier, 2005 dos posibilidades para comprender el camino de la cognición desde nuestra disciplina:

1) Distinguir el cognitivismo y su programa ideológico-político de naturalización de las disciplinas entre ellas la neurociencia.

2) Clarificar la epistemología general de las ciencias de la cultura. Hay que caracterizar la distinción epistemológica entre las ciencias de la cultura y las ciencias de la naturaleza. Dicha distinción se ocuparia tanto de los hechos como del modo de conocimiento.

Pero para poder comprender dicho camino es conveniente pensar en que si bien es cierto que el lenguaje participa en la cognición, ello no quiere decir necesariamente que la lingüística sea una ciencia cognitiva. Es más, no todas las ramas de la lingüística se interesan en este modelo. Citaremos y comentaremos a continuación algunas tesis especificas de autores que, a nuestro juicio, se convierten en argumentos que despliegan un amplio abanico de posibilidades epistemológicas de la lingüística cognitiva y enlazan las dos posibilidades citadas más atrás con lo anunciado por Lazard (2005).

En la constelación disciplinar formada por las ciencias cognitivas, la lingüística se encuentra integrada con las demás ciencias humanas y algunas ciencias sociales en un paradigma que incluye también a las ciencias llamadas "exactas" o "duras". Ahora bien, esta cohabitación motiva la cuestión por el estatus de la lingüistica y su lugar en el seno de la constelación. La lingüística se ocupa en efecto de un objeto empirico, el lenguaje, sobre el cual la experimentación no es posible en las mismas condiciones que otros campos. Ella no tiene acceso directo al tipo de fenómenos que atraen la atención de la investigación cognitiva dura ya que si trata objetos como la lengua, las oraciones, los enunciados, no está preparada en lo absoluto para abordar los procesos mentales que gobiernan su producción. El desfase se acentúa además, durante los dos últimos decenios, de técnicas innovadoras de observación, extremadamente sofisticadas, permitiendo una mejor y más amplia comprensión del sistema nervioso: registro de la actividad de neuronas individuales y del conjunto del cerebro, explicación de los procesos perceptuales $y$ cognitivos en términos de actividad bioquímica, modelización computacional

${ }^{157}$ Sobre esta problemática véase Chomsky, 1965 y 1972.

${ }^{158}$ Esta es la tesis que se presenta y defiende en Rastier y Bouquet 2002 
de estos procesos. El hecho de que el proyecto cognitivo integre como pieza maestra a su dispositivo esta dimensión experimental y tecnológico lleva a preguntarse si la lingüística cognitiva puede ser algo diferente de una psicolingüistica o una neurolingüistica. Rouveret (2004, 29-30. Traducción nuestra).

Entre las ciencias del lenguaje, sólo una nos interesa aqui, la lingüística. Por supuesto todo tipo de disciplinas toman como objeto el lenguaje: psicología cognitiva, neuropsicologia, sociologia (según Bourdieu), filosofía del lenguaje. La lingüística es la única que tiene como objeto exclusivo el lenguaje, aprehendido a través de la diversidad de lenguas. De esta manera, ella es, en términos estrictos, la única ciencia del lenguaje. Así también, ella puede encontrar puntos de contacto con las demás disciplinas que se ocupan del lenguaje y sobretodo con aquellas que participan en la investigación cognitiva. Pero podemos estimar igualmente con razón que el objeto real de la lingüistica está constituido por las lenguas y que trata de su diversidad (diversidad contrastiva, diversidad de los estados sincrónicos, diversidad de los estados diacrónicos). Desde este punto de vista el lenguaje sería una abstracción sin valor explicativo fuera de una tipología; - simplemente un nombre cómodo para designar el conjunto de los universales de método (como los conceptos de fonema, silaba, predicación, etc.) En consecuencia, concebida de esta manera, la lingüística no tiene una relación inmediata con las demás disciplinas que se ocupan del lenguaje.
En el ámbito de las investigaciones cognitivas, es evidentemente la primera concepción la que prevalece. Rastier $(2011,101)$.

Tanto Rastier como Rouveret se preocupan por distanciar lo que sería una lingüistica tout court, autónoma y preocupada en forjar modelos teóricos concentrados en la dinámica estructural de las lenguas humanas de una lingüística cognitiva fruto de la emergencia de las teorías cognitivas y su correspondiente influencia en la teoría lingüística. Esto es lo que denuncia -y por ende confirma- Lazard en el resumen de su artículo: La expresión "lingüística cognitiva" solo tiene sentido en el contexto de la lingüistica norteamericana, en donde significa la oposición a la gramática generativa y a la concepción del lenguaje como un módulo autónomo. Fuera de este contexto, ella solo designa, el retorno a una concepción tradicional del lenguaje, de la lengua y de la lingüística. Ella corre el riesgo sin embargo de perder de vista la especificidad del análisis de las estructuras de las lenguas ${ }^{159} \cdot \mathrm{La}$ lingüística general ha tenido como misión estudiar la estructura, la función y el funcionamiento de las lenguas. Además tiene un objetivo que, en término de Moreno Cabrera $(1995,15)$ "es el de descubrir y enunciar las leyes que determinan el funcionamiento específicamente lingüístico de las lenguas humanas." ¿Qué es lo que lleva entonces a que los estudiosos intenten modificar el lexema lingüistica con el adjetivo cognitiva?

En su reciente artículo, el profesor Gilbert Lazard llevó a cabo una reflexión polémica en donde su tesis central era que la lingüística cognitiva no existía, no al menos fuera del deseo de sus heraldos californianos ${ }^{160}$. Según él, el término de ciencias cognitivas designa un conjunto de disciplinas que como la neurobiología, la psicologia, o la inteligencia artificial, "toman

Lazard, 2005, 3. La traducción es nuestra.

Cf. Cuenca \& Hilferty, 1999. 
como objeto aspectos diversos de la actividad sensorial e intelectual por la cual el ser humano conoce el mundo que lo rodea. Ahora bien, dice él que si se incluye a la lingüistica en este conjunto, en nombre de los lazos entre el lenguaje y el pensamiento, entonces "toda lingüística es cognitiva". Por el contrario, si se le excluye en virtud de la especificidad de los fenómenos lingüísticos y que se le considera como una disciplina conexa pero totalmente diferente, entonces "ninguna lingüística es cognitiva". Tanto en uno como en otro caso, la noción de lingüística cognitiva es oscura.

Las teorias lingüísticas que se autoproclaman cognitivas estarian en su totalidad confrontadas al siguiente dilema. Por un lado, ellas volverian a la concepción tradicional de la lengua como un sistema simbólico que conjuga forma y sentido. Por el otro ellas saldrían del campo propio de la disciplina buscando motivaciones externas a los fenómenos lingüísticos observados o inferir las propiedades generales de la mente humana a partir de esas observaciones. En el primer caso, se trataría solo de la lingüística en el sentido clásico del término; en el segundo, ya no sería la lingüística sino otra disciplina. En cuanto a los instrumentos intelectuales como es el caso por ejemplo de los conceptos de 'representación' 'prototipo', 'mapa cognitivo', etc., los lingüistas se ven avocados a buscar ayuda en otros campos disciplinares para obtener préstamos conceptuales y así formular sus tesis de apoyo. Pero eso generaría una confusión de identidad tanto del lingüista como del propio discurso científico de la lingüistica pues cuando se trata de comprender su dinámica epistemológica hay que mencionar su relación con las ciencias conexas precisando con sumo cuidado dos aspectos: (i) cuáles son los rasgos que la caracterizan como una ciencia que al ocuparse del lenguaje y de las lenguas la hace diferente a otras disciplinas que tratan los mismos objetos, y (ii) determinar cuál es el aporte teórico y metodológico de los demás campos disciplinares, diferentes a la lingüística que complementan su visión. Lazard es inflexible a este respecto:

¿De qué manera la lingüistica puede beneficiarse del desarrollo del "programa cognitivo" y de qué manera puede contribuir a su desarrollo? Si el lingüista -y hablo del lingüista "de las lenguas", no del psicolingüista ni del sociolingüista ni incluso aquel que se identifica con la "lingüística del habla"puede beneficiarse de un contacto con las demás disciplinas, es por un lado, como ya lo vimos, tomando prestados instrumentos intelectuales. Pero a decir verdad, para lograr esto no hay que limitarse en principio a las disciplinas vecinas: él puede tomar lo suyo donde quiera que se encuentre. Asi sucede, particularmente con el tipologista que compara las lenguas con el fin de descubrir invariantes: él puede, para equiparse de una base de comparación, alimentar su inspiración en lo cognitivo [...] Por otro lado, cuando un invariante ha sido descubierto, es perfectamente legitimo ampliar el horizonte buscando relaciones en uno $u$ otro sentido, entre este fenómeno lingüístico y otros que proceden de las disciplinas conexas, es decir de aspectos del "funcionamiento de la mente humana". Pero esto ya no es lingüística. $(2005,15)$

Si nos mantenemos al margen del elemento extradisciplinar que se concentra en la contextualización cultural y geográfica, este tipo de modelos indica un retorno a la concepción tradicional del lenguaje y al detrimento de la especificidad de la estructura de las lenguas. Para autores como Victorri, Fuchs, Gardner y otros, la lingüística cognitiva lleva la impronta chomskyana, pero es conveniente distinguir dos de sus campos 
más conocidos: las gramáticas cognitivas (GC) y las gramáticas generativas (GG). A la lingüística cognitiva se le reconoce una unidad temática que, a través de varias formulaciones teóricas intentan dar cuenta de los conocimientos específicos que maneja la mente humana a través de la facultad del lenguaje. No obstante, son los modelos teóricos producidos, difundidos y liderados por la escuela californiana conformada por autores tan reconocidos como Langacker, Lakoff, Johnson, Fauconnier y demás formulando respuestas propias sobre las estructuraciones del lenguaje frente a las operaciones mentales que le subyacen. Cada nivel de análisis lingüístico estaría impregnado de características de estas operaciones que podrían seleccionar lo lexical, lo sintáctico, lo morfológico e incluso lo semántico.

Presentaremos ahora algunas de las ideas correspondientes a las Escuelas de Cambridge (gramáticas generativas) y de California (gramáticas cognitivas) como bases de los modelos teóricos americanos de la lingüistica cognitiva.

\subsection{Escuela de Cambridge ${ }^{161}$}

En el artículo que se ocupa de clarificar las particularidades de la facultad del lenguaje, escrito junto con Hauser, y Ficht titulado The faculty of Language: What is it, Who has it and How Did it Evolve? Chomsky refuerza la idea de que el lenguaje puede concebirse como un órgano cualquiera del cuerpo y bajo este criterio metafórico, desarrolla su programa de investigación biolingüístico:

We argue that an understanding of the faculty of language requires substantial interdisciplinary cooperation. We suggest how current developments in linguistics can be profitably wedded to work in evolutionary biology, anthropology, psychology, and neuroscience. We submit that a distinction should be made between the faculty of language in the broad sense (FLB) and in the narrow sense ( $F L N)$. FLB includes a sensory-motor system, a conceptualintentional system, and the computational mechanisms for recursion, providing the capacity to generate an infinite range of expressions from a finite set of elements. We hypothesize that FLN only includes recursion and is the only uniquely human component of the faculty of language. We further argue that FLN may have evolved for reasons other than language, hence comparative studies might look for evidence of such computations outside of the domain of communication (for example, number, navigation, and social relations). ${ }^{162}$

Como es costumbre en los medios académicos norteamericanos, dicha propuesta causó escozor y provocó múltiples reacciones entre las que se encuentra la del dúo dinámico Pinker \& Jackendoff pero que no comentaremos aquí 163 . Chomsky et al. no hacen más que proponer un marco para investigar la evolución del lenguaje haciendo énfasis en la consideración de un enfoque empírico e interdisciplinario además de precisar las diferentes nociones del concepto "lenguaje" tan dispersas en los estudios técnicos. El lenguaje es un fenómeno complejo que supone una pluralidad de puntos de vista, todos válidos según el diseño del modelo teórico seleccionado.

\footnotetext{
${ }^{61}$ Esta sección se basa en la interpretación de Milner, 1989, 240 y siguientes. Escogimos a Milner porque es un autor que se mantiene en una posición central y objetiva frente al paradigma chomskyano.

${ }^{162}$ Science Vol. $298^{\circ} 22$ November 2002, p. 1569

${ }^{163}$ Remitimos al inquieto y perverso lector al texto The Faculty of Language: What's Special about it? autoria de Pinker y Jackendoff publicado en Cognition 95 (2005) 201-236
} 
Así pues, el punto de vista según el cual el lenguaje es una facultad humana es perfectamente aceptable y plausible en las ciencias cuyo objeto exige una observación de las diversas facultades del ser humano: neurología, psicología, neurobiologia, biologia, etc. Aunque los datos lingüísticos (i.e. gramaticales), paralelamente a otro tipo de datos, hayan servido de referencia a estas ciencias que estudian las facultades superiores humanas, la lingüística en sí misma se limita a considerar que la FL existe pero la asume a través del estudio de sus manifestaciones más elaboradas como lo son las lenguas y sus respectivos textos.

El programa chomskyano se puede ilustrar asi:

El pensamiento es un tratamiento de la información; es por eso que se le llama cognición. Según esta terminologia, la ciencia cognitiva no es más que una teoria cientifica de los procesos que comprometen de alguna forma una actividad de pensamiento consciente o inconsciente: en resumen, es una versión posible de la psicologia científica que la noción de órgano mental requiere.

El tratamiento de la información es una manipulación de símbolos. Llevados a su estructura abstracta, los computadores cumplen con manipulaciones de símbolos según las reglas que les fijen los respectivos programas. El funcionamiento del pensamiento es pues homogéneo en su estructura y la base material del pensamiento (el cerebro) se deja representar como un computador o un conjunto de computadores conectados.

Las reglas que siguen los computadores son de naturaleza lógica. El programa cognitivista tiene una gran importancia. Desde el punto de vista teórico, su audacia reside esencialmente en el punto lógico que permite aseverar lo siguiente: la lógica o al menos algunas de sus partes son un instrumento de conocimiento de la naturaleza. Desde un punto de vista empírico, la puesta en marcha del programa aparece de manera desigual. Entre las realizaciones más sobresalientes, conviene citar los trabajos de Marr ${ }^{164}$. Hay que citar también la ciencia del lenguaje: el lenguaje en cuanto órgano mental, compromete al pensamiento y cae en el campo de la psicología científica ${ }^{165}$. Esta última en su versión cognitivista, permitirá comprender que la actividad del lenguaje, como la actividad de cualquier órgano mental, no es más que la puesta en marcha de instrucciones de tipo informático.

Más aún, es interesante constatar que a partir de un programa de investigación definida y delimitada de manera estricta, varias vías de investigación se hayan desarrollado paralelamente: son tan diversas (no más obsérvese la diferencia entre Cambridge y California) y sus representantes mantienen una lucha de poderes francamente feroz ${ }^{166}$. Una de estas vias es la escuela chomskyana. Es por eso que una ciencia del lenguaje que quiera ser digna de tal nombre no puede contentarse con teorizar únicamente sobre la lengua; debe teorizar también sobre la producción de la lengua, La escuela de Cambridge se ha distinguido por hacer valer su 'neutralidad' entre las dos posiciones. Desde su perspectiva, no haya que escoger entre reconocimiento $y$ producción ya que sus principios son los mismos y están ligados específicamente por el concepto de 'regla' cuya noción constituye el fundamento del cognitivismo en materia de lenguaje.

\footnotetext{
${ }^{164}$ Consúltese su libro Visión, 1980.

${ }^{165}$ Reglas y representaciones, 1980 , ofrece un buen panorama.

${ }^{166}$ Sobre las luchas de poder en los campos cientificos véase Bourdieu 1975, 1984 y 2001. Para el caso de las luchas lingüisticas, cf. Newmeyer, 1980, Emonds et al., 1976 y Koerner 2004.
} 
Jenkins (1997) ${ }^{167}$ elabora una sintesis interesante sobre los postulados biológicos del modelo chomskyano:

We can divide up the study of the biology of language into three main areas: 1) language, 2) development of language and 3) evolution of language. The study of the first area, "language," tries to answer the question of what it means to know a language; i.e., to "know English," "know Japanese," etc. The language faculty is that "component of the human mind/brain that is specifically dedicated to knowledge and use of language." The hypothesis that there is such a faculty specifically dedicated to language is sometimes called the "modularity hypothesis." The language faculty itself is sometimes called a "language organ." The language faculty is composed of two systems: a cognitive system, for storing information and, possibly, performance systems specifically dedicated to language. There are, we assume, also performance systems outside the language faculty.

These include sensorimotor systems (for articulation and auditory perception) and conceptual-intentional systems-classically, these are systems involving sound and meaning.

A "language," then, is a "state of the language faculty." We say that we "know" or "have" a language L, knowing; e.g., such things as rhyme, entailment, phrase boundaries, anaphoric relations, etc. A language generates expressions, each of which is a pair of interface levels, a PF (phonetic) representation and an LF (semantic) representation. These representations are generated in a computational component which combines (merges) items from a lexicon and rearranges them in various ways.

The study of the second area, "development of language, "tries to answer the question about what internal states language passes (or "grows") through, from an initial, genetically determined, state (S0) to a final steady state (S-n). The linguist's theory of the final state is called grammar and the linguist's theory of the initial state is called Universal Grammar (UG). Universal Grammar might be regarded as the theory for the biological Bauplan for human language. Finally, the study of the third area, "evolution of language, "tries to answer the question of how language evolved in the species and discover what the evolutionary "design" specifications of language were, functional or otherwise.

\subsection{Escuela de California}

Nos limitaremos a comentar algunas características de la escuela californiana a partir de la lectura del libro editado por $\mathrm{G}$. Fauconnier et E. Sweetser: Spaces, Worlds and Grammar, 1996.

El concepto clave es el de 'espacios' que se definen como construcciones mentales pero también discursivas ya que se construyen, se relacionan entre si y se desarrollan a medida que el discurso tiene lugar. ${ }^{168}$ Fauconnier es el inventor del término. Este término de 'espacios' representa en la lingüística cognitiva (LC) el aspecto mentalista de la teoría. La LC es así una teoría esencialmente semántica, pragmasemántica subjetivista, e incluso representacionalista. Esto quiere decir que el

${ }^{167}$ Biolinguistics - Structure, Development and Evolution of Language

${ }^{168} \mathrm{Y}$ lo define asi: "Mental spaces are small conceptual packets constructed as we think and talk, for purposes of local understanding and action. They are very partial assemblies containing elements, and structured by frames and cognitive models. They are interconnected and can be modified as thought and discourse unfold" 
lenguaje se relaciona con el mundo (o con mundos si se echa mano de la teoria de los mundos posibles semánticos). Entonces si la LC es subjetivista también es objetivista. Pero la representación debe ser considerada como tal y no como una simple linguistic reflection del mundo tal como es. La representación es una construcción mental de un espacio mental. En palabras de los editores: From a linguistic perspective, this [volume] provides substantive explanations for the forms and meanings of many grammatical constructions. From a cognitive science perspective, it shows how rich language data, if properly understood, can serve to reveal aspects of higher-level representation (Fauconnier \& Sweetser, 1996: 1).

Del lugar que ocupe y del peso que tenga el sujeto en esta teoria, se deducirá fácilmente a través de su punto de vista sobre el mundo, la importancia del contexto en donde este sujeto evoluciona y en donde enuncia. Así, si la LC es considerada y reconocida como una lingüística encarnada (embodied es el término inglés), no se puede olvidar el papel que juega el entorno.
Nuestro editores asi lo confirman: If human cognition is so contextually configured, it is crucial to examine what sorts of connections our minds tend to make, and what sorts of effects are produced by different contexts. The examination of linguistic usage is a powerful tool for such a cognitive study (Fauconnier \& Sweetser, 1996: 2).

Por otra parte el 'uso' lingüístico es por decirlo de alguna forma una marca de fábrica de la lingüística cognitiva californiana. Esta tendencia le permite tomar distancia del cognitivismo lingüístico chomskyano y de las diferentes teorias estructuralistas y generativas que resultaron a lo largo de los años 60 y 70 . En la cognición situada la idea central es que la construcción de conocimientos, por ejemplo en situación de aprendizaje, moviliza todos los recursos del medio social y cultural y no solamente las habilidades culturales. Lo cognitivo no se distingue de lo social sino que se complementa. El siguiente esquema, tomado de Geeraertz $(1987,5)$ ilustra las características de la escuela californiana.

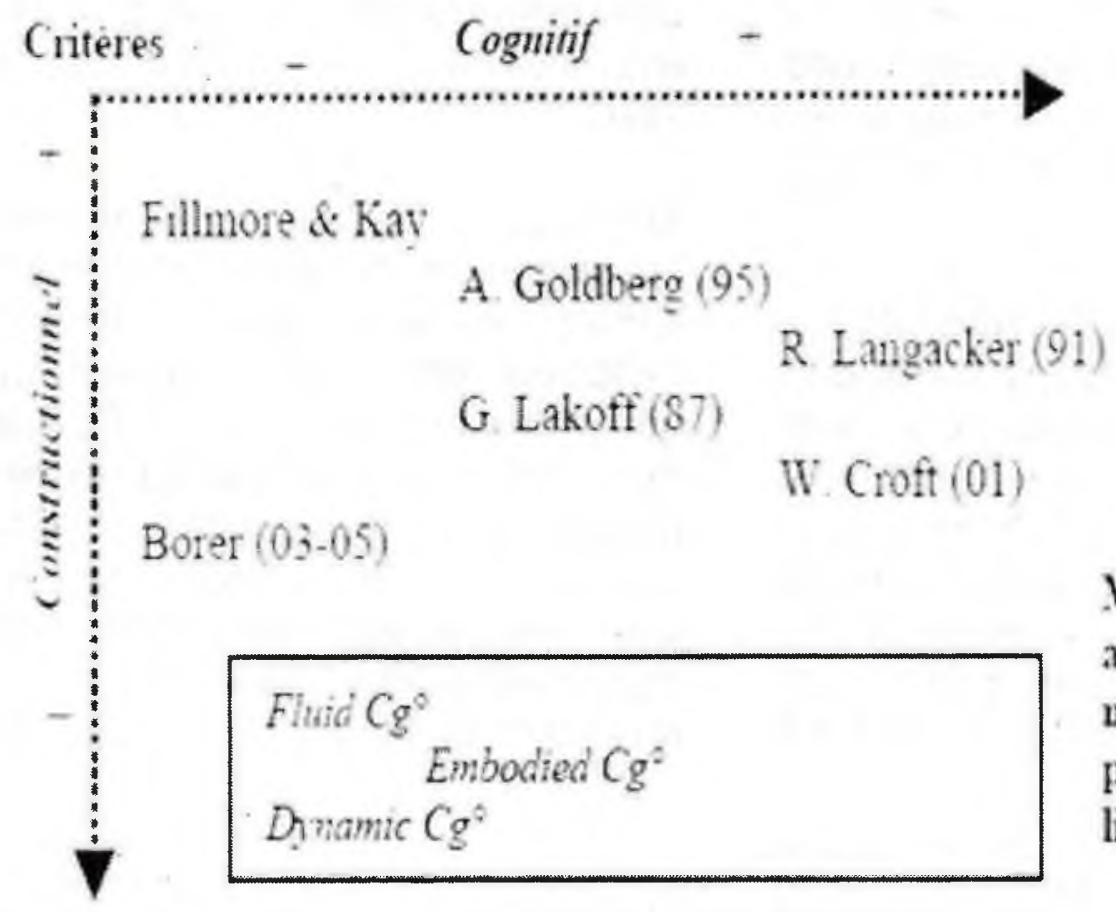
Modèles a application non - purement linguistique. 
La sintesis del programa californiano la presenta Maldonado 2011 (269-270):

Un rasgo común de distintas escuelas cognoscitivas es reconocer en toda formación lingüística cargas específicas de significado asociadas a modos de conceptualización. En forma particular, la gramática cognoscitiva (GC), introducida por Ronald Langacker en sus dos volúmenes ya clásicos (1987, 1991a), expandida en dos volúmenes posteriores (Langacker 1991b, 2000) y diversificada en una amplia variedad de publicaciones, se define como un modelo analítico que intenta ofrecer explicaciones lingüisticas de la estructura de la lengua que, por una parte, sean psicológica y biológicamente plausibles y que, a su vez, respondan a las manifestaciones de la lengua en su uso real ubicadas en contextos naturales de interacción social como se presentan en el discurso. La orientación cognoscitiva del modelo consiste en buscar la base conceptual del lenguaje incluso en sus funciones más simples de interacción lingüistica. Desde esta aproximación, la lengua encuentra sus fundamentos operativos en habilidades y sistemas cognoscitivos básicos, como la percepción, la memoria y la categorización, facultades de las que el sistema lingüistico no se puede separar. En lugar de ser vista como una entidad independiente, la lengua se explica a partir de su coincidencia con una serie de habilidades mentales fácilmente demostrables. Las peculiaridades innatas que pueda haber en el lenguaje no son sino adaptaciones particulares de fenómenos cognoscitivos más básicos y no entidades independientes construidas con modos de operación autónoma. Algunas manifestaciones de esas habilidades lingüístico-mentales son la facultad de formar conceptualizaciones estructuradas, la de emplear una estructura como base para categorizar otra estructura alterna, la de establecer correspondencias entre distintas estructuras, la de concebir una situación con distintos niveles de abstracción (esquematización), la de combinar estructuras simples para formar estructuras de mayor complejidad y la de asignar distintos niveles de prominencia a los elementos que conforman una escena.

2. Representaciones, Prototipos, Emotividad y Comunicación

\subsection{Generalidades}

Pocos profesionales que trabajan en el sector educativo han considerado la emoción como algo accesorio en materia de aprendizaje. No obstante, la dimensión emocional se presenta como lo opuesto a la lógica y a la razón. Más aún, la polarización entre razón y emoción o entre cognición y emoción ha polarizado el pensamiento occidental y sobretodo a las ciencias, de ahí las dicotomias cuerpo/mente, naturaleza/cultura, masculino/femenino, etc., que modelan nuestras visiones, representaciones y acciones. Desde esta perspectiva, las maneras de concebir el aprendizaje están orientadas cada vez más a orientar las acciones hacia la racionalidad "pura", es decir, liberadas de todo rasgo animal y sentimental. Tanto Platón como Descartes e incluso Kant, cada uno desde su propuesta teórica, ha fortalecido esta polarización sobretodo haciendo explícita la consagración de la hegemonía de la razón sobre la emoción y asociando la primera a la mente y la segunda al cuerpo.

Este dogma es tan fundamental que sólo para tener el derecho a contradecirlo, hay que acudir al discurso' hegemónico per se, es decir por medio de la misma razón. Esto es lo que se produjo a finales del siglo XIX con el movimiento psicoanalítico cuando diferentes pensadores comenzaron a utilizar la razón para atacar la 
propia hegemonía de la razón. Es lo que sucedía desde las primeras declaraciones iniciadas por Freud (siendo él un médico neurólogo) sobre el papel de las emociones en la vida intelectual, social, espiritual, etc., y que hoy en día es visible, tangible, observable, demostrable en el plano cientifico. De hecho, los avances tecnológicos extraordinarios en el transcurso de los últimos años han permitido refinar de manera espectacular nuestra observación del cerebro humano. Así, es posible interesarse en la vida emotiva y cognitiva pero no de forma especulativa o indirecta, sino de manera bien documentada, concreta e incluso empírica. Basta con estudiar a Llinás 2003, Damasio 1999, Estas observaciones han permitido confirmar las relaciones permanentes $y$ continúas que mantienen las redes neuronales asociadas a lo que denominamos, coloquialmente, razón y emoción. Cuando por ejemplo luego de un accidente que afecta el cerebro, se destruyen los lazos entre los sistemas neuronales relacionados con la emoción y con la razón, ya las cosas, el mundo dejan de tener sentido y valor. De hecho las lesiones de algunas partes del cerebro perturban tanto los procesos de razonamiento y de toma de decisión así como la expresión y la percepción de las emociones, sobretodo en el dominio personal y social (cf. Damasio 1995). Sin embargo, las partes del cerebro como por ejemplo la amigdala, implicadas en la evaluación emotiva de los objetos o situaciones realizan una acción que en términos de velocidad, preceden a la acción del neocortex que, se dedica al reconocimiento y al análisis de los objetos o situaciones. Frente a un fenómeno ${ }^{169}$, lo que cuenta primero es su percepción emotiva (miedo, placer, tristeza, alegria, cólera, ternura, etc.).

Todos tenemos emociones, y sabemos más o menos lo que es una emoción, incluso si la comunidad especializada de psicólogos y neurólogos no coinciden plenamente en una definición unificadora. El término "emoción" se relaciona, en la creencia popular, con las pasiones; en un sentido más amplio, se considera como el conjunto de estados afectivos cualquiera que sea la intensidad y la duración. El proceso emotivo se percibe con fuerza en la comunicación lingüística (i.e. verbal) y es precisamente en este fenómeno que vamos a detenernos un momento.

En el transcurso de una conversación, son muchos los momentos en donde se manifiestan las reacciones de tipo afectivo y que se pueden comprobar observando las modificaciones de los procesos fisiológicos (variación del ritmo cardiaco, sudoración, alteración de la respiración, etc.) Estos momentos emocionales se relacionan directamente con frases cortas y se acompañan de gestos, mímica, silencio y a veces sonrisas. Aún así, cuando se le solicita a algún hablante que mencione de manera espontánea cuáles fueron los momentos de mayor emotividad sólo mencionan los más intensos dejando de lado aquellos que a su juicio fueron los menos representativos. Hay algunos estados afectivos/emotivos como el odio, la hostilidad, la molestia y el goce erótico que logran prolongarse de manera continua durante periodos largos de tiempo y su oscilación es variable.

En una interacción tête-à-tête el que habla se plantea con frecuencia preguntas del tipo: "¿me entiende?", "¿me estará escuchando?", "¿le interesa lo que pienso y digo?", "¿qué pensará?", etc., y por su parte, el oyente también se pregunta: "¿qué quiere decir?", "¿por qué lo dice?", "¿cuál es su propósito?" Este tipo de preguntas muestra que las representaciones mentales de los individuos

${ }^{169}$ A este respecto consúltese Damasio 1995, Goleman 1997 
generan estados de empatía, entendida ésta última como el lograr compartir estados psicocorporales semejantes en el momento de la interacción. Es un fenómeno común en las aulas de clase por ejemplo.

Si tratamos de explicar este fenómeno desde el campo lingüístico cognitivo podemos afirmar que la fuerza dinámica de la mente humana se manifiesta porque las necesidades comunicativas del ser humano constituyen el factor fundamental que desencadena los mecanismos psicológicos de los cambios semánticos. Las lenguas cambian porque los seres humanos intentan expresar sus sentimientos da manera exacta y satisfactoria como les sea posible.

Los estudios semánticos no ignoran las experiencias vividas ni el medio cultural en donde se desenvuelve el humano que usa una lengua particular. Si el lenguaje es una de las herramientas conceptuales del hombre no necesariamente tiene que ser estudiado de manera independiente o autónoma sino que puede ser considerado en su relación cognitiva: interpretar, fijar, ordenar, preguntar, razonar, discriminar, en síntesis expresar lo que en términos de Benveniste podemos definir como la experiencia humana. Dicha experiencia puede ser por supuesto individual - colectiva (representación social). Esto implica que se necesita hacer énfasis en las diferencias de representación de los modelos que consolidan las experiencias.

Uno de los tópicos de mayor relevancia en el área de la lingüística cognitiva es el tipo de tejido elaborado por las propias categorias naturales permitiéndole asegurar una coherencia interna. A la pregunta: ¿Qué es lo que mantiene una categoría organizada alrededor de prototipos y específicamente hasta dónde las significaciones de un grupo polisémico pueden distanciarse entre ellas o del núcleo prototípico sin que sean rechazadas por la categoría? Mejor aún, la pregunta puede ser reformulada en función de las relaciones establecidas entre las significaciones: ¿cuáles son las relaciones que se pueden calificar de aceptables? ¿Se presentan de manera escalonada? Y si es así, ¿hasta dónde llegan?

\subsection{Representaciones, Categorización y Prototipos}

En un trabajo anterior, mencionamos que Los principios de la Estructuración de Conocimientos por Dominios (ECD) pueden ser considerados como una prolongación crítica de los trabajos realizados en psicologia y en etnología sobre los conceptos y las estructuraciones conceptuales y que dieron nacimiento a la teoría de los prototipos. Esta teoría se desarrolló en reacción a la teoria 'clásica' (es decir la teoría según la cual un concepto puede ser por un conjunto de condiciones necesarias y suficientes). Más exactamente, la teoría de prototipos estaba dirigida contra la versión psicológica de esta teoría, versión que postulaba que para poseer un concepto, habría que conocer su definición; en otros términos, tener una representación mental de este concepto que consiste en una lista de propiedades necesarias y suficientes.

En los años 70, Eleanor Rosch fue una de las figuras más representativas en el trabajo con los prototipos, mostró, junto con sus colaboradores ${ }^{170}$ que la teoría clásica interpretada como teoría psicológica no permitía

${ }^{170}$ Rosch, 1973, 1975a, 1975b, 1975c, 1977; Rosch et al., 1976; Rosch y Lloyd, 1978; Rosch y Mervis, 1975.

${ }^{171}$ Los psicólogos prefieren generalmente el término de 'categoria', al de 'concepto', asociado de manera muy estrecha a la teoria clásica. Sin embargo, este uso da lugar a ambigüedades, pues el término de 'categoria' se usa tanto para hablar de una clase de objetos en el mundo (extensión), tanto para hablar de la representación mental de esa clase (intensión). Para evitar esta ambigüedad, se volverá a utilizar el término 'concepto' que se utilizará para hablar de la representación mental y se reservará el uso de la palabra 'categoría' para las clases de objeto en el mundo. 
dar cuenta de un conjunto de fenómenos de categorización. Si los conceptos ${ }^{171}$ son definidos únicamente por las propiedades que todos los miembros de la categoria comparten, ningún miembro de una categoría debería ser mejor ejemplar que otro. Ahora bien, Rosch y su equipo pusieron en évidencia la existencia de fenómenos llamados de "tipicalidad": algunos ejemplares de una categoría aparecen como "mejores" que otros. Así, para dar algunos ejemplos, perro aparece como un ejemplar más representativo de la categoria animal que tortuga, fusil como ejemplar más representativo de la categoria arma que cuchillo, agua como una bebida más representativa que té $y$ así sucesivamente. Además, los juicios directos que hacen los hablantes se manifiestan de diferentes maneras:

Tiempo de categorización: es más corto para los ejemplares más típicos.

Errores de categorización: son menos numerosos para los ejemplares juzgados como más típicos.

Orden de aprendizaje: los nombres de los ejemplares más típicos se aprenden en primer lugar.

Orden de producción: cuando se le pregunta a los hablantes citar nombres de ejemplares de una categoría, los ejemplares más típicos se citan en primer lugar.

Puntos de referencia cognitiva: los ejemplares más típicos son los que se escogen con mayor facilidad como puntos de referencia cognitivos.

Varias explicaciones de estos fenómenos han sido propuestas. Se ha sugerido que la tipicalidad estaba ligada a la familiaridad con los ejemplares o con la frecuencia lexical de los nombres que las designan. De manera más general, la interpretación que fue dada por estos resultados experimentales es que los fenómenos de tipicalidad revelan que los miembros de una categoria no son iguales y que os conceptos poseen una estructura interna que favorece los miembros típicos con relación a los menos típicos. De allí vino la idea que los conceptos no están representados mentalmente por un conjunto de propiedades necesarias y suficientes sino bajo la forma de un prototipo, es decir, una entidad abstracta que combina las propiedades típicas de la categoría. Paralelamente, la teoría de los prototipos no concibe la categorización como un proceso de verificación de condiciones necesarias y suficientes sino como un procedimiento de apareamiento: se decide ubicar un objeto en una categoría en función de su grado de similitud con el prototipo.

La teoría de los prototipos se ha ido puliendo poco a poco. Concibiendo la categorización como un proceso de apareamiento, la teoría de los prototipos es llevada a asimilar la pertenencia categorial y la representatividad pero en términos de grado. (Armstrong, Gleitman y Gleitman, 1983) que incluso categorías tan bien definidas como la de los números impares dan lugar a fenómenos de tipicalidad. Pero no porque 3 y 7 se consideren más típicos que 61 por ejemplo que 61 es menos impar que 3 y 7 . Sucede lo mismo con las categorías de especies naturales. El gerbo es un ave menos típica que la golondrina, pero no es un ave diferente para considerarla otra cosa. Se debe pues renunciar a la idea de que los fenómenos de tipicalidad son el reflejo directo de la estructura conceptual y considerarlos como efectos superficiales que pueden tener fuentes diferentes.

Encontramos también otro tipo de confusión en la teoría de los prototipos, y tiene que ver con los dominios. Los trabajos de Rosch se han ocupado sobretodo de los conceptos de objetos, artefactos y especies naturales, pero estos dos dominios de objetos no fueron distinguidos. Las conclusiones a las cuales han llegado los estudios que se ocupan de las especies naturales fueron entendidas sin haber tomado precauciones frente al dominio de los 
artefactos e inversamente, los resultados que conciernen los artefactos fueron extendidos a las especies naturales. Así la noción de de prototipo, elaborada principalmente sobre las categorias de especies naturales, en donde las actividades de categorización se efectúan en una amplia medida sobre la base de propiedades perceptivas, fue aplicada sin cambio al dominio de los artefactos. Ahora bien, si se estudia de cerca el dominio de los artefactos, se percibe que las propiedades importantes para la categorización son menos propiedades perceptivas que propiedades funcionales (por ejemplo, "para sentarse" en el caso de la silla): En la categorización de los artefactos, pero no en la de las especies naturales, interviene de manera central el carácter finalizado de las actividades humanas.

Veamos ahora con mayor detenimiento la hipótesis de ECD. Esta hipótesis postula que los conceptos poseen una estructura mucho más rica que la propuesta por la teoría prototípica fundamentada en la noción de similitud de rasgos. Postula además la existencia de dominios de base que poseen principios de organización que les son específicos, principios que determinan en parte cuáles atributos aparecen como los más representativos y cuáles son las correlaciones que se notan. Esas correlaciones conforman la categorización.

La categorización, como proceso mental de organización de pensamiento, no se realiza a partir de condiciones necesarias y suficientes que determinan fronteras infranqueables entre las categorias cognitivas, sino a partir de estructuras conceptuales, relaciones prototípicas y de semejanza de familia que determinan límites difusos entre categorias.

El lenguaje tiene un carácter inherentemente simbólico. Por lo tanto, su función primera es significar. De ello se deduce que no es correcto separar el componente gramatical del semántico: la gramática no constituye un nivel formal y autónomo de representación, sino que también es simbólica y significativa.

La gramática consiste en la estructuración y simbolización del contenido semántico a partir de una forma fonológica. Así pues, el significado es un concepto fundamental y no derivado en el análisis gramatical.

Se impone una caracterización dinámica del lenguaje que difumina las fronteras entre los diferentes niveles del lenguaje (la semántica y la pragmática, la semántica y la gramática, la gramática y el léxico) y muestra las dificultades e inadecuaciones que resultan de la aplicación rigida de ciertas dicotomías, como la que opone diacronía y sincronía, competencia y actuación, denotación y connotación.

La gramática es una entidad en evolución continua, "un conjunto de rutinas cognitivas, que se constituyen, mantienen y modifican por el uso lingüístico" (Langacker, 1987:57).

El universo mental humano no se limita a la utilización de los signos lingüísticos: Los conceptos -entendidos en un primer momento como las ideas o representaciones que el humano hace de algo y cómo ese algo tiene presencia en el mundo-, expresados con la ayuda de las expresiones verbales sólo constituyen una parte de nuestra representación. Los conceptos que estructuran nuestra manera de pensar son categorías conceptuales que agrupan fenómenos comunicativos en su conjunto. Nuestras categorías conceptuales se fijan en parte en las categorías lingüísticas. La mayoría de signos lingüísticos se remiten a un contenido conceptual especifico y la categoría lexical en la cual aparecen muestra la manera como se ha concebido. De igual forma existe también ún número reducido de categorias gramaticales que determina el marco estructural más amplio de la lengua. Esto quiere decir que todos los miembros de una categoría no poseen el mismo estatus ya que al lado de los elementos 
prototípicos están también los periféricos. Veamos algunos casos:

Una categoria lexical (i.e. clase) como la de "silla" se compone de subtipos o subcategorías.
Algunas de ellas representan mejor la clase que otras. El elemento más representativo, el más utilizado de la categoría es denominado el prototipo o miembro prototípico de la categoría.

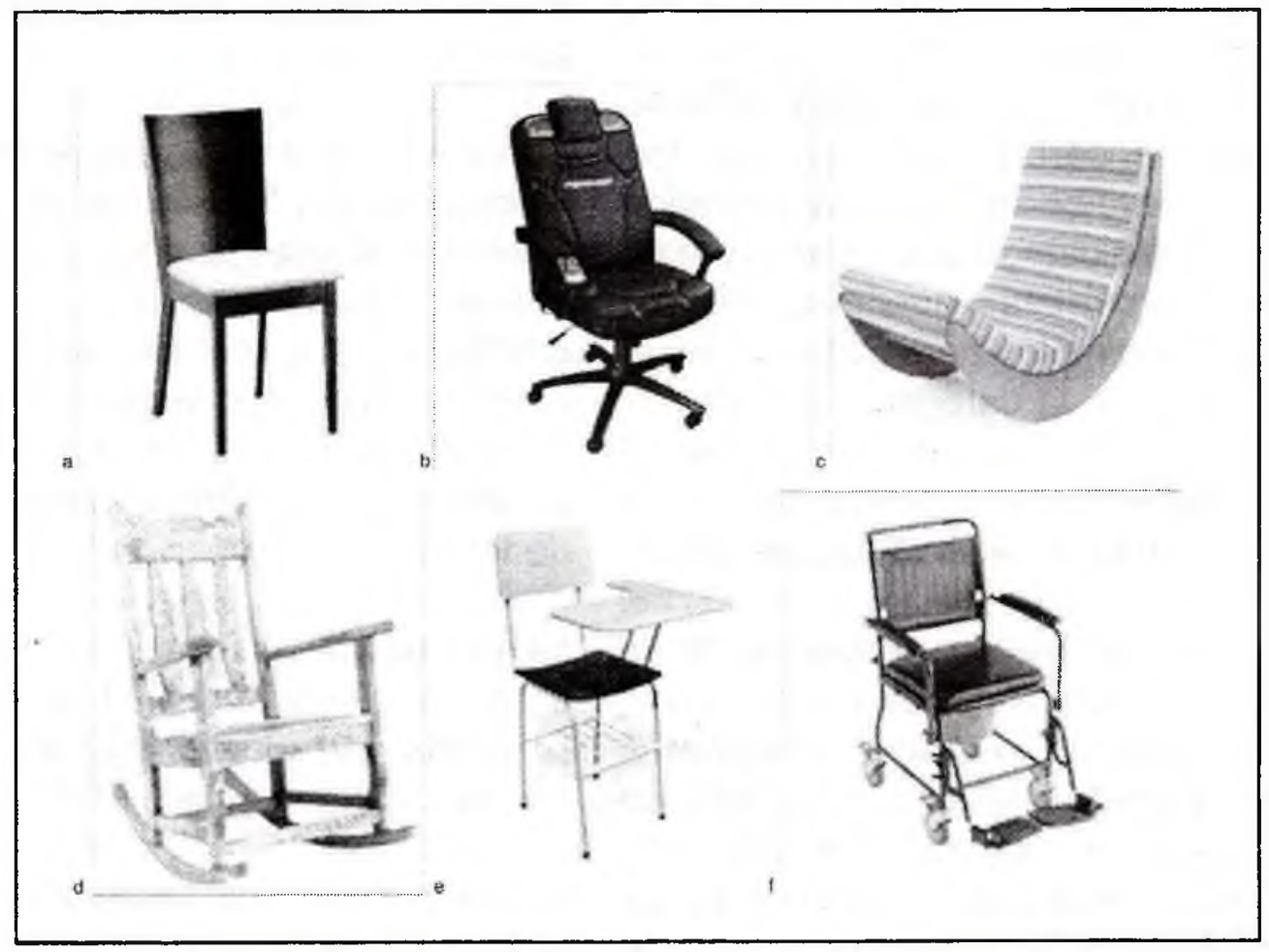

Figura 1: Categoria y subcategoría de SILLA. Fuente propia

El elemento prototipico de la figura 1 , sería la silla a).

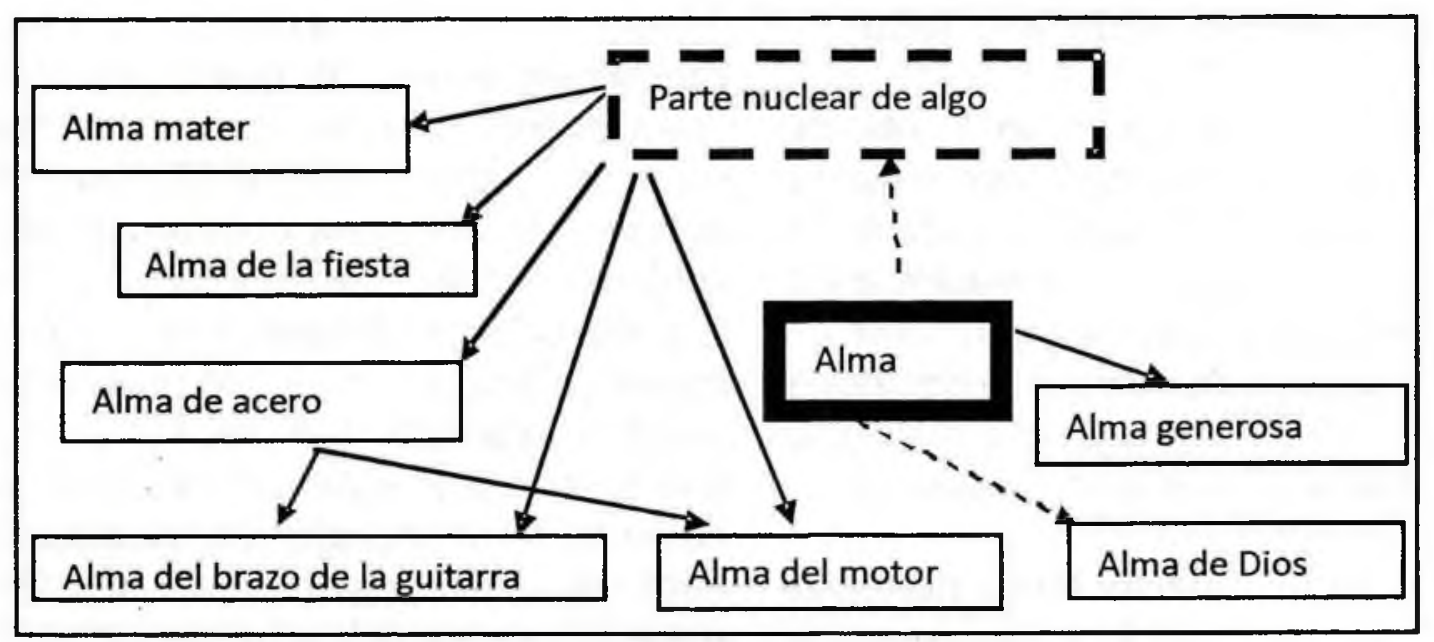

Figura 2: Red semántica elaborada. Fuente, Maldonado 2011,275 
Maldonado propone en su gráfica la reconstitución de una red semántica (i.e. red conceptual) aclarando el papel del elemento "alma":

Es sospechoso que la locución alma de una fiesta esté a la misma distancia del esquema que la expresión alma del brazo de la guitarra. El alma de la fiesta es sin duda una elaboración del esquema en virtud de que alguien es la parte central de una fiesta, pero no es menos cierto que la expresión está más relacionada con el significado del prototipo 'centro emocional' que las demás expresiones que conforman la red. Por su parte el alma del brazo de la guitarra parece desprenderse, al igual que el alma del motor, no sólo de la noción de centralidad proveniente del esquema, sino también de la extensión alma de acero de manera que la relación con el significado más general se establece indirectamente a través de un nodo extensional. En caso de ser esto cierto contamos una organización en la que mientras alma de una fiesta se liga directamente al prototipo, tanto el alma del motor, como alma del brazo de la guitarra se desprenden de una extensión del prototipo que se nutre también del esquema, en cuyo caso la red semántica debería tener la organización(...) indicada.

Otro caso interesante es el de los dominios conceptuales, entendidos como tipos de imágenes activadas dependiendo de un proceso previo de jerarquización de la información, motivado por niveles de representación. El juego infantil "stop" es una muestra de ello. Presentamos un esquema sencillo que explicita el principio del mencionado juego:

\begin{tabular}{|c|c|c|c|c|c|}
\hline \multirow{2}{*}{ Niveles } & \multicolumn{5}{|c|}{ Dominios Conceptuales } \\
\hline Genérico & Planta & Animal & Vestido & Vehículo & Fruta \\
\hline De Base & árbol & perro & pantalón & automóvil & naranja \\
\hline Específico & roble & labrador & jean & jaguar & tánguelo \\
\hline
\end{tabular}

Gráfica 1: Dominios conceptuales. Fuente propia

Puede representarse igualmente en uno de sus niveles:

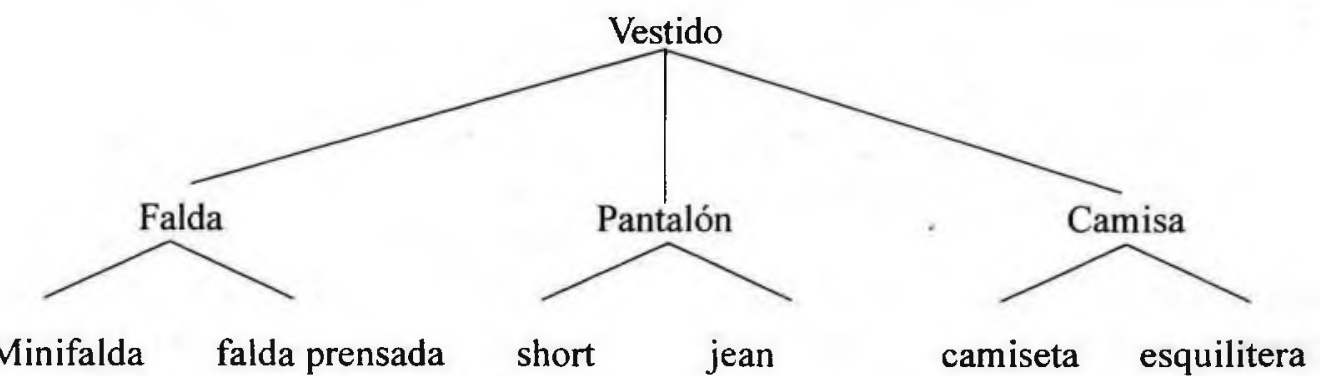

Gráfica 2: Variación hiperonómica. Fuente propia 


\section{Panda Suncolombiana 17}

Otros ejemplos de representación: Eva no solo es la compañera de Adán sino que también es su perdición a causa de una manzana. Bueno eso es lo que nos han dicho y por ende hemos interiorizado, representado. Eva se encontró frente a la manzana que le ofreció la serpiente y tuvo la posibilidad de llevar a cabo dos acciones. En la primera acción, Eva toma la manzana y se la come. Los modelos bioquímicos de la nutrición encargados de describir dicha acción, propondrán modelos de transformaciones físicas de la manzana al interior del sistema digestivo de Eva. La segunda acción, Eva puede establecer una relación con la manzana y esta puede hacer parte de ella en términos cognitivos sin ningún tipo de contacto físico. Eva recuerda la manzana, la representa cuando Dios los cuestiona Los modelos teóricos que explicarían esta relación dirian que hay un mediador, un sustituto. En una descripción generosa de este sustituto, se puede decir que la manzana está 'representada' en el agente, es decir es representada en Eva pero de manera diferente; Eva y la manzana son una representación.

En un curso de escritura creativa, la hábil y reconocida profesora, distribuye entre los asistentes dos breves textos (cf. Infra) que ella misma escribió pero atribuye su autoria a escritores diferentes para luego preguntar: ¿Qué ideas les suscitan estos textos?, ¿les gusta? ¿Quién pudo haberlos escrito? ¿Cómo podemos iniciar una historia original a partir de su fusión? Hay múltiples respuestas al intentar explicar qué significan los textos. Los participantes hablan a partir de sus experiencias previas, de sus representaciones mentales y de los mundos posibles que pueden construir paralelos a la lectura y generar escritura, autogeneración y por ende representación.

El escritor piensa en ella y desea que esté bien. No la acompaña en cuerpo pero su alma está alli, sus anhelos están alli, su respiración y amor están juntos y en cada poro de esa piel que será besada por el sol, acariciada por la brisa y bañada por el agua marina... Llegó el día. Me levanto creyendo que me dirijo a esa universidad a escuchar a la ponente central que hablará del ELE, la música y algo de ajena y esquiva cognición. Siento la exposición, me encanta el mensaje de respuesta como muestra de agradecimiento (¿a qué más aspiro?) y luego el silencio de la cotidianidad. Me alegro por Josiane.

Para una mañana calorosa, era apenas esperable que fuera sorprendida por los avatares del día. Aqui es entonces donde intento decir lo particular, muy particular que en cualquier momentos nos puede pasar. Ella quien a simple vista no cautiva todas las miradas y al parecer no es su intención escuchar chiflidos por cada pasillo que pase. Lleva en su cabeza el accesorio del dia: una bobina azul, que además de todo está tejida. Su piel es trigueña, su rostro es algo ovalado, sus cejas forman una figura entre circular $y$ recta, sus cejas no son del todo definidas. Además debo mencionar, que sus ojos no son demasiados expresivos, parece haber detrás de ellos un claro rastro de tristeza; ¿a causa de qué? ¿Amor? ¿lnconformidad? ¿Angustias? ¿Ansiedad? Tantos interrogantes que se me ocurren y quizás su propia voz nos dé la respuesta.

La representación es pues conocimiento y es además establecimiento de relaciones. Veamos lo que dice a propósito Arboleda (2011, 175):

La sintaxis del conocimiento humano deviene de la sintaxis del mundo representado y de la manera como el humano lo percibe, de las relaciones que establece, de la manera como lo organiza. En el pensamiento $y$ el conocimiento humanos se establecen, entre otras, 
relaciones de carácter atribucional entre los elementos del mundo conocido y pensado. En el conocimiento de una hoja seca se piensa la sequedad como una característica de la hoja, como un rasgo de la hoja; en èse sentido, se le atribuye. Pero en efecto, la mano de una persona no penetra en la piedra de manera como penetra en el agua; en esa medida, la representación de la piedra como impenetrable y del agua como penetrable es para el humano una representación motivada.

En ese orden de ideas, el concepto de 'representación' sirve para designar de manera general el siguiente hecho: cuando un agente cualquiera se relaciona cognitivamente con su entorno, construye un estado interno que le activa una imagen particular de ese entorno y la posibilidad de traerlo cuando lo crea necesario. Aquí nos formulamos un interrogante: ¿De qué naturaleza es el tipo de relación que se establece entre el agente y su entorno? Mejor, ¿De qué naturaleza es la relación establecida entre un estado interno y su objeto externo? Para responder adecuadamente podemos decir que se dan tres tipos de representación de acuerdo al tipo de relación entre el agente y su respectivo entorno.

\section{Representación como inscripción}

En los escritos técnicos de la ciencia cognitiva, el primer espacio teórico en donde aparece la representación es en donde se explica cómo un estado interno se crea cuando los órganos de captación de un agente (p.ej. los ojos, la nariz, las manos, etc.) son afectados por un objeto externo. Cuando son afectados producen un estado físico interno, llamado también 'sensación'.

\section{Representación como clasificación}

En este nivel de representación se deben explicar las operaciones que un agente debe realizar para jerarquizar la multitud de representaciones como inscripción que le llegan permanentemente. Es el trabajo cerebral más riguroso y complejo. Se retiene lo que se discrimina.

\section{Representación como categorización}

En este espacio teórico, se explican cuáles son las operaciones que el agente realiza sobre las representaciones clasificadas. Aquí se destaca el punto subjetivo ya que se debe explicar cómo es que el agente se sitúa con respecto a las representaciones y sobretodo, cómo logra interrelacionarlas para construir un sistema complejo de creencias y relacionarlas armónicamente con su entorno. Desde un punto de vista cognitivo, jerarquizar los estímulos es categorizar. Un ser humano por ejemplo, percibe objetos de su entorno pero solo él es capaz de determinar cuáles son los objetos que le permiten llevar a cabo una acción exitosa, en un momento particular. Pensemos en un sobreviviente de un terremoto. Bajo los escombros solo dispone de su orina para mantenerse vivo y no morir de sed. En un primer nivel de categorización, la orina no es representada como líquido para ingerir. Hace parte de los líquidos no ingeribles como la gasolina, el aceite, etc. Pero en circunstancias extremas como las mencionadas se recategoriza y pasa a ser parte de la categoria líquido ingerible como el agua, la cerveza o la gaseosa.

Estos tres tipos de representación pueden sintetizarse en un modelo posible del universo conceptual humano, tal como se propone en Delbecque, 2002,33: (ver gráfico siguiente)

Para comprender el proceso de comunicación humana hán surgido una gran cantidad de modelos teóricos desde las respectivas teorías científicas. Como no vamos a repetirlas para no agotar a nuestro exigente lector (lector in fabula mezclado a veces con el lector hembra), 


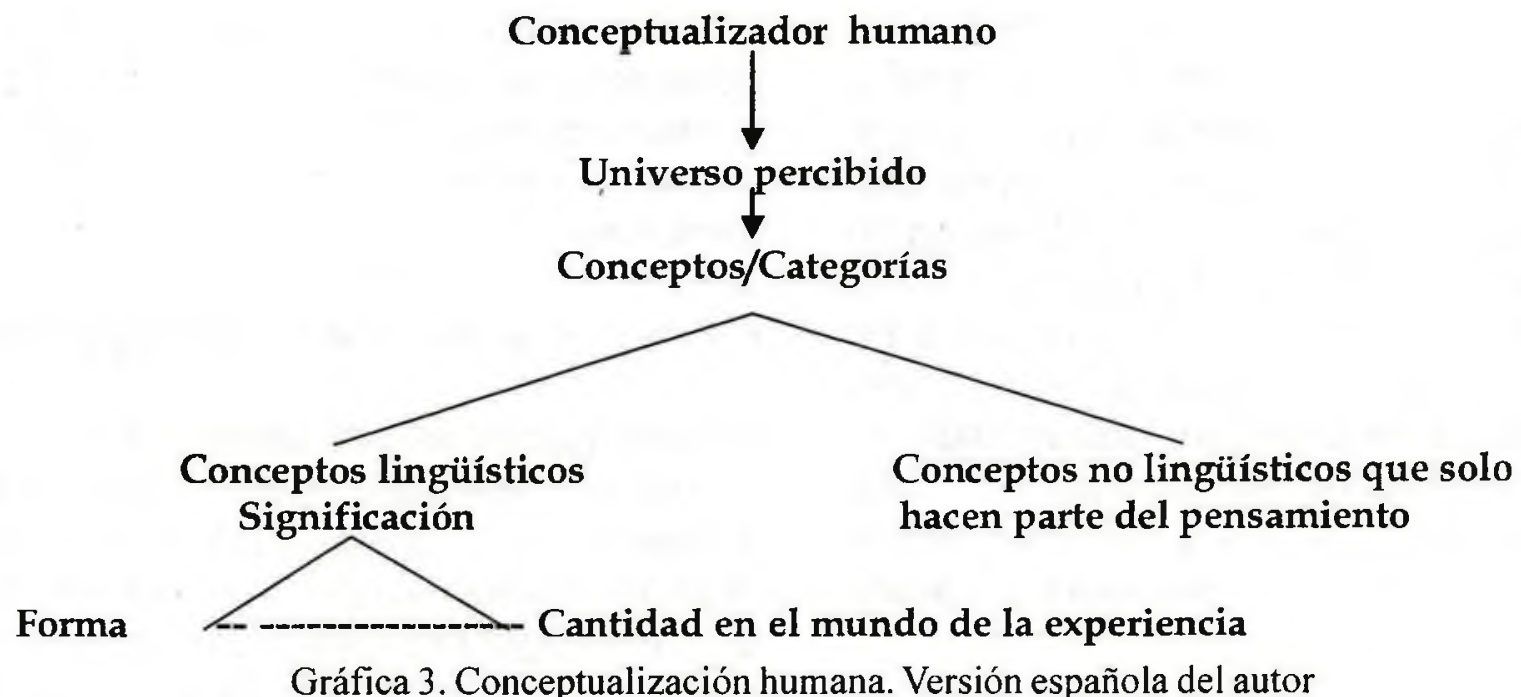

indicaremos un elemento que podría aportar una nueva lectura de la comunicación. Se trata de los mapas cognitivos.

\subsection{Mapas cognitivos}

Se le atribuye a Tolman (1948), especialista en psicología animal, la paternidad del término "mapa cognitivo". Tolman sostenía que una rata ubicada en situación de aprendizaje como la de orientarse en un complejo laberinto, lograba desarrollar un mapa cognitivo de su entorno y dicho mapa tenía un efecto determinante en su comportamiento. Tolman insistía en el carácter flexible del comportamiento indicando que la rata manifestaba una gran capacidad de adaptación a los cambios hechos por el experimentador entre los que se cuenta, cambiar la posición del punto de partida en el laberinto. Como conclusión, se podía apreciar que el concepto de mapa cognitivo podia ayudar a comprender algunos mecanismos psicológicos presentes en la comunicación.

A lo largo de los años, la metáfora del mapa cognitivo constituyó el foco de interés de varios estudios, sobretodo desde los trabajos de Axelrod (1976) y su equipo en el dominio de la política internacional. De igual manera es interesante anotar que en una gama variada de capos disciplinares, diferentes investigadores utilizaron la idea de mapa cognitivo en sus trabajos y particularmente para el área de la economía y la administración en las subespecializaciones de comportamiento organizacional, marketing emotivo, gestión estratégica, sistemas de información organizacionales y actitudes y representaciones mentales.

Veamos a continuación algunas definiciones de mapa cognitivo que dan una idea general de su constitución:

Un mapa cognitivo es un modelo concebido para representar la manera como una persona define un problema particular pero nao debe considerarse como el modelo general de pensar de un individuo.

La cartografía cognitiva es una herramienta de negociación que facilita la reflexión y la toma de decisiones inmediatas e importantes.

El mapa cognitivo es la representación del conocimiento almacenado en nuestros cerebros, gracias a las experiencias vividas y acumuladas a través de nuestro proceso de emoción y sentimiento. ${ }^{172}$

${ }^{172}$ Definiciones tomadas de Axelrod, 1976 
Si nos interesa particularmente la comunicación e interacción humanas, una definición posible sería la siguiente: Representación gráfica de la representación mental que un investigador se hace de un conjunto de representaciones discursivas enunciadas por un sujeto a partir de sus propias representaciones cognitivas, con relación a un objeto en particular. ${ }^{173}$

\section{Mapas cognitivos y comunicación discursiva ${ }^{174}$}

Es el discurso producido por un sujeto en un contexto de interlocución particular a partir de sus propias representaciones cognitivas que guía al investigador en la fabricación de un mapa cognitivo. ¿Se le ha cruzado por la mente a algún analista del discurso local hacer algo como eso? Es poco probable. Es conveniente caracterizar el proceso de elaboración de un mapa cognitivo acudiendo por ejemplo a la noción de esquematización ${ }^{175}$ de Grize (1982, 1984 y 1989) quien la desarrollo de manera notable $y$ es de alli que tomamos las ideas más relevantes.

Las representaciones discursivas pueden ser vistas como el resultado de una actividad de esquematización a la cual debe someterse el sujeto para producir los materiales que va a utilizar el investigador para fabricar el mapa cognitivo. La esquematización ${ }^{176}$, noción clave de la lógica natural, se caracteriza por los siguientes rasgos:

a) Una esquematización es la puesta en discurso

b) Del punto de vista que un hablante $A$

c) Se hace -o tiene- de cierta realidad $R$.

d) Esta puesta en discurso es realizada por un interlocutor, o un grupo de interlocutores, $B$

e) En una situación de interlocución dado (los lingüistas también afirman que contexto $=$ df lo que acompaña al texto. ${ }^{176}$

Así pues, la esquematización es una actividad orientada hacia la producción de un discurso. Es a partir de esta expresión oral o escrita del pensamiento de un hablante que define una situación u organiza su experiencia que el investigador determina los conceptos y los lazos que le permitirán trazar el mapa cognitivo de este sujeto. Claro está que el investigador no puede determinar a priori los conceptos de una carta cognitiva sin correr el riesgo de despojar al hablante de un elemento clave de sus representaciones cognitivas (los tres tipos de representaciones que se mencionaron en el acápite anterior).

Un investigador traza un mapa cognitivo a partir de la representación mental que él se hace de los objetivos propuestos por un individuo ya sea en presencia o ausencia del investigador. El mapa cognitivo requiere de la reconstrucción de una producción lingüística. En ese orden de ideas, el objetivo del mapa (las

${ }^{173}$ Audet, 2006

${ }^{174} \mathrm{Lo}$ discursivo como simbólico tal como lo afirma Gambarara: E il linguaggio? Questa "forma di comunicazione simbolica" si è evoluta perché gli uomini hanno cominciato a sviluppare una "vita cooperativa di gruppo". L'obiettivo è un "equilibrio riproduttivo": se la vita cooperativa favorisce la sopravvivenza allora ci sarà bisogno di evitare le controversie e stabilire chi "ha obblighi verso l'altro" e di che natura. Inoltre, parallelamente, c'è il bisogno di sapere se gli altri sono d'accordo. Questa sorta di contratto sociale sta alla base dello sviluppo della "facoltà simbolica". Ci sono cose che non si posson rappresentare senza simboli. La "pace" è una di queste. Ma per far sì che questo ragionamento possa aver luogo negli antenati vi deve esser stata per forza la presenza di una facoltà simbolica a determinare l'agire collettivo ed in seguito quello comunicativo. Un linguaggio di tipo simbolico, dunque, sorge per rinsaldare i rapporti tra uomini di una comunità. $E^{\prime}$ un linguaggio che agisce, performativo, usato per coordinarsi ed, in primo luogo, per comunicare.

${ }^{175}$ Dicha esquematización remite a la actividad de representación. Esta actividad designa al tiempo una forma de actividad humana y el resultado mismo de dicha actividad que termina siendo la entidad simbólica en si misma. La representación es al mismo tiempo un proceso y el producto de dicho proceso. Lo mismo vale, haciendo la extensión, para el elemento discurso.

${ }^{176}$ Grize, 1989,154) 
representaciones discursivas de un individuo) como proceso de reconstrucción, es tejer su representación mental, aquella que se hace de las representaciones discursivas que busca cartografiar. Es lo que en otros modelos teóricos se ha denominado 'tejido discursivo'.

La base del mapa cognitivo es la imagen de interpretación (identificación de la representación) que puede resumirse como

$[E \leftrightarrow t \leftrightarrow H]: \quad$ Sea un enunciado, definido como una secuencia fónica determinada producida por un individuo determinado $\mathrm{H} \mathrm{a}$ partir de un tiempo determinado $t$ y que construye sentido así:

"Sentido a la izquierda $[E \leftrightarrow t \leftrightarrow H]$ : , concebido como un conjunto complejo y estructurado de hechos que están en relación causal con lo dicho por el hablante en cuestión en el tiempo en cuestión. Se denominará conjunto causal (CC) a este conjunto.

Sentido a la derecha, de este $[\mathrm{E} \leftrightarrow \mathrm{t} \leftrightarrow \mathrm{H}] \mathrm{que}$ resulta de una serie de operaciones que se mantienen entre las relaciones denominadas como el espacio interpretativo. Este espacio está compuesto por individuos efectuando operaciones evocadas (i.e. representadas) y se les denomina interpretantes (INT)

El manejo de los sentidos constituyen las instancias de validación (elementos del mapa cognitivo) que pueden definirse como los hechos internos derivados de los hechos externos y que reflejan instituciones ${ }^{177}$ (escuela, familia, religión, prensa), textos (la Biblia la Constitución Política, El Espectador, El Tiempo, un manual de lingüística), personas (el padre, la madre, el amigo, el profesor, el enamorado), y prácticas (leer, escribir, discutir, demostrar, argumentar, chismosear, pelear, amar). Hay que destacar que una instancia de validación no

\footnotetext{
${ }^{177} \mathrm{Cf}$. La Mediologia de R. Debray.

$178 \mathrm{http}: / / \mathrm{www}$.ual.es/Universidad/Depar/dmce/Congreso/ Seminario\%20ll $/ 42 \% 20$ Mellado.pdf
}

constituye la huella de una persona sino de la persona en proceso de interacción con el mundo.

Veamos cómo a partir de una entrevista que se le realizó a un profesor de Física se levantó un mapa cognitivo; el ejemplo es tomado de Mellado Jiménez : 178

(Antes se le había preguntado si existen criterios racionales para decidir si una teoria puede considerarse científica):

Pregunta David-58: ¿Los criterios son universales y objetivos o dependen de otros factores?

Respuesta David-58: [Hay factores extracientificos que hacen que se acepte una teoria y no se acepte otra.]58.1 [Por ejemplo la teoria heliocéntrica tardó tanto tiempo en aceptarse por factores ajenos a la ciencia. 758.2 [Aunque al final se acaba aceptando si verdaderamente es buena.]58.3 [Por ejemplo lo que decíamos antes de la teoria de la relatividad que tardó bastante en aceptarse por un asunto un poco de tradición. Porque suponia cargarse lo que habia antes y eso es muy duro.]58. 4 [No es un criterio estrictamente científico] 58.5

En nuestro caso los mapas cognitivos son construidos inicialmente por los investigadores, y posteriormente son evaluados y corregidos por el propio profesor. A continuación mostramos algunos de los mapas de David sobre la naturaleza de la ciencia.

Este profesor considera que las teorías científicas reflejan sólo nuestro conocimiento de la realidad, no la realidad misma. Aunque lo fundamental es la prueba experimental, cree que el progreso del conocimiento científico es un proceso complejo al que se llega por una interacción entre pensamiento y realidad y en el que también intervienen factores extracientíficos:

"Hay factores extracientíficos que hacen que 
se acepte una teoría y no se acepte otra" ( $D$ 58)

Considera que las teorias cambian cuando se encuentra un experimento crucial que falla, es decir las teorias no se prueban por verificación sino por falsación, tal como defendía Popper: "Una teoría es verdadera hasta que nos demuestran que es mentira. Hasta que hay un hecho experimental que no cuadra con 10 tuyo." (D-66.2).

"Algunos experimentos son cruciales, siempre ha habido experimentos que han destronado una teoria" (D-68.1).

David tiene también rasgos de la metodología de Lakatos cuando defiende que las teorias se reformulan por confrontación entre si; $y$, por último piensa que las teorías cambian porotras que resuelven más problemas, tal como indicaba Laudan. Considera básica la prueba experimental, y se quedaria con las teorias que resuelvan más problemas, y que sean más elegantes y más globales. En todo caso se decide por el criterio de parsimonia, que ya expresara Guillermo de Occan en el siglo XIV, de elegir las teorias más sencillas entre las que cumplan las condiciones requeridas.

"Cuando se tienen dos teorias enfrentadas me quedaría con la que resuelve más problemas" (D-62)

;"Ante dos teorias que tengan validez experimental se escoge la más sencilla de argumentos" (D-57.1)

"Una teoria lo más global posible" (D-93.1)

El siguiente mapa cognitivo es el resultado de la entrevista:

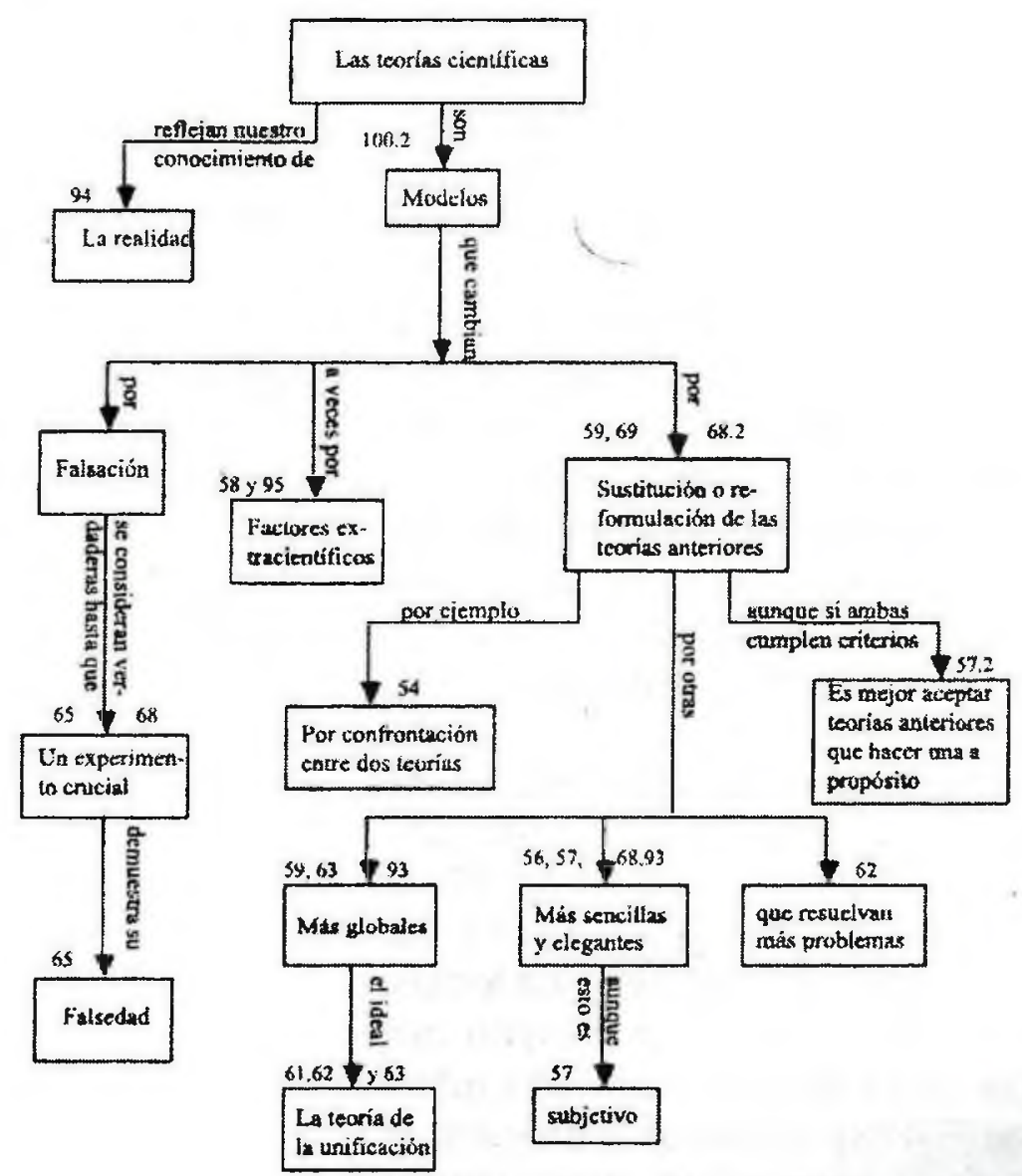




\section{Proyecciones}

Los procesos comunicativos en la Universidad Surcolombiana están, utilizando una expresión que nunca ha pasado de moda, en crisis. Para no suscitar prurito en el ego de algunos miembros de la comunidad institucional, se puede proponer la realización de talleres para el diseño de mapas cognitivos cuyo fin sería el de elaborar procesos de negociación en el trabajo universitario. Dicho en otros términos, determinar los roles que tanto profesores y estudiantes deben asumir a la hora de coconstruir conocimiento. De esta forma se tornarian en una herramienta de mayor impacto, los cursos de comunicación lingüística, los de análisis del discurso, los de pedagogía universitaria y los Hermes de la comunicación interna: Usconexión, Orni, página web de la USCO y algunos boletines sueltos de secciones académico/administrativas.

Pero, ¿qué tipo de herramientas podriamos utilizar para llevar a cabo las proyecciones? $\mathrm{Si}$ es el trabajo en el aula de clase, se parte de lo programado por un profesor en su microdiseño curricular. Se traza un mapa inicial teniendo en cuenta cada uno de los items propuestos previo a su respectivo diligenciamiento. Es lo que constituye la instancia de validación mencionada supra en la situación en donde el profesor diligencia -llena- el microdiseño curricular y los estudiantes interpretan dicho mensaje. De ahí se postulan dos mapas que determinan el proceso de representación mental de los interlocutores.

De igual forma los boletines de Usconexión, Orni y la misma página web de la USCO constituyen una configuración particular que se devela a partir del análisis de la distribución no sólo de la información sino de las imágenes y los temas recurrentes. Un ejemplo lo constituyen las 'últimas' noticias universitarias. Cómo se explica en términos de [E?t?H] cuando se le pregunta a un miembro de la comunidad universitaria:
¿Cuál es el impacto del programa $X$ en la dinámica social de la USCO? ¿Cuándo tendrá lugar la próxima rendición de cuentas?, etc.

Los registros escritos -archivos-y las entrevistas a miembros de la comunidad académica de la USCO nos ayudarían a levantar mapas cognitivos que reflejan la dinámica comunicatival discursiva de sus miembros.

\section{Bibliografía}

Se citan los textos básicos que contienen todas las referencia citadas.

Maria Joseph Cuenca y Joseph Hilferty. Introducción a la lingüística cognitiva. Barcelona, Ariel: 1999.

Ronald Langacker. Concept, Image, and Symbol. The Cognitive Basis of Grammar. Mouton de Gruyter. Berlin-New York: 1991.

Noam Chomsky. Passim.

Howard Gardner. La nueva ciencia de la mente. Barcelona, Paidós: 1988

Miguel Ángel Mahecha. Antología de Lingüística Cognitiva. Neiva, Editorial Universidad Surcolombiana. 2011.

Gilbert Lazard. La Linguistique cognitive n'existe pas. Bulletin de la Société de linguistique de Paris CLL/1. 2007 